\title{
Influence of hydrogen on the regeneration of boron-oxygen related defects in crystalline silicon
}

\author{
S. Wilking, ${ }^{\text {a) }}$ A. Herguth, and G. Hahn \\ Department of Physics, University of Konstanz, 78457 Konstanz, Germany
}

(Received 18 February 2013; accepted 23 April 2013; published online 17 May 2013)

\begin{abstract}
When exposed to light, boron doped monocrystalline Czochralski grown silicon suffers from degradation of the minority carrier lifetime due to the formation of recombination active boron-oxygen related defects. The so called regeneration procedure is able to convert these recombination active defects into a new less recombination active state characterized by a higher minority charge carrier lifetime and stability under illumination. However, the exact working principle on microscopic scale is still unknown even though some influencing factors were identified. The role of hydrogen in the regeneration process is investigated in this work. We find that the characteristic regeneration time constant is subject to variation depending on the process parameters of a Plasma Enhanced Chemical Vapor Deposition a-SiN $\mathrm{N}_{\mathrm{x}}: \mathrm{H}$ deposition, namely the applied gas flows, as well as on the thermal history of the sample prior to applying the regeneration procedure. The positive effect of a short high temperature $\left(800-900^{\circ} \mathrm{C}\right)$ step leads to the idea that the presence of atomic hydrogen in the silicon bulk is crucial for the regeneration effect to occur. The different regeneration behavior of samples with variable thickness of a hydrogen diffusion barrier, namely an $\mathrm{Al}_{2} \mathrm{O}_{3}$ layer capped by $\mathrm{SiN}_{\mathrm{x}}: \mathrm{H}$, supports those results. Finally, the importance of hydrogen for regeneration is directly shown on samples having different hydrogen bulk concentrations due to direct hydrogenation in a Microwave Induced Remote Hydrogen Plasma reactor. A new model to explain the effect of the regeneration of boron-oxygen related defect centers based on the possible role of atomic hydrogen is presented. (C) 2013 AIP Publishing LLC. [http://dx.doi.org/10.1063/1.4804310]
\end{abstract}

\section{MOTIVATION}

The material quality of oxygen-rich boron doped crystalline silicon is typically limited by a low minority carrier lifetime due to recombination active boron-oxygen (BO) related defect centers. ${ }^{1-3}$ Herguth et al. have shown that a so called regeneration procedure consisting of a combination of carrier injection (by light or forward biasing) and slightly elevated temperatures between 60 and $200^{\circ} \mathrm{C}$ causes the degraded material to permanently recover its bulk lifetime. ${ }^{4,5}$ Therefore, the regeneration step is an excellent way to permanently improve the minority carrier lifetime and, e.g., the efficiency of solar cells based on boron doped Czochralski $(\mathrm{Cz})$ grown material.

Until now it has been shown that the effectiveness of the regeneration procedure scales with the concentrations of different defects in silicon, like boron, ${ }^{6}$ interstitial oxygen, ${ }^{7}$ thermal donors, ${ }^{6}$ or metal impurities. ${ }^{8}$ In addition to that, Münzer ${ }^{9}$ has shown that no regeneration could be observed on samples coated with LPCVD (Low Pressure Chemical

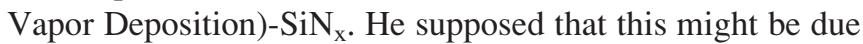
to the fact that LPCVD $\mathrm{SiN}_{\mathrm{x}}$ does not contain hydrogen in significant amounts-in contrast to Plasma Enhanced Chemical Vapor Deposition (PECVD) $\mathrm{SiN}_{\mathrm{x}}: \mathrm{H}$. This leads to the assumption that hydrogen has a major influence on the regeneration behavior of boron-oxygen degraded silicon wafers. Lim et al. ${ }^{10}$ noted that the observed differences in the regeneration behavior between samples passivated with

\footnotetext{
a) Author to whom correspondence should be addressed. Electronic mail: Svenja.Wilking@uni-konstanz.de.
}

LPCVD $\operatorname{SiN}_{\mathrm{x}}$ and those passivated with PECVD $\mathrm{SiN}_{\mathrm{x}}: \mathrm{H}$ do not necessarily have to be explained by a hydrogen-based effect, but can also be explained by the absence of a plasma during LPCVD SiN ${ }_{\mathrm{x}}$ deposition. Further systematic data concerning a possible influence of hydrogen on the regeneration process as well as a new model to explain this effect is provided in this work.

\section{GENERAL EXPERIMENTAL SETUP}

Lifetime samples made from $2 \Omega \mathrm{cm}$ boron doped $\mathrm{Cz}$ grown silicon wafers with interstitial oxygen concentrations about $5 \times 10^{17} \mathrm{~cm}^{-3}$ were used for all experiments presented in this paper. Wafers were laser cut into pieces of $5 \times 5 \mathrm{~cm}^{2}$. After saw damage etching and $\mathrm{HCl} / \mathrm{HF}$ cleaning, they received a gettering step realized in form of a $\mathrm{POCl}_{3}$ diffusion $\left(\sim 1 \mathrm{~h}\right.$ at $\left.\sim 840^{\circ} \mathrm{C}\right)$. Phosphorus silicate glass and emitter were removed thereafter in diluted HF and by a chemical polishing procedure, respectively. Details of the surface passivation layers (symmetrically deposited on both sides) will be given separately for all experiments. Standard deposition parameters of the different deposition systems are reported in Table I. In some cases, $\mathrm{SiN}_{\mathrm{x}}: \mathrm{H}$ layers were characterized using a Vertex 80 FTIR (Fourier-Transformed InfraRed) spectrometer from Bruker Optics.

For measuring the regeneration behavior, the complete regeneration procedure was applied: The samples were first annealed for $10 \mathrm{~min}$ at $200^{\circ} \mathrm{C}$ in the dark, then completely degraded at $40^{\circ} \mathrm{C}, 0.2 \pm 0.1$ suns, ${ }^{11}$ and finally regenerated at $130 \pm 2{ }^{\circ} \mathrm{C}, 0.6 \pm 0.1$ suns. ${ }^{12}$ Minority carrier lifetime was measured at a fixed injection level of $0.1 \mathrm{~N}_{\mathrm{A}}$ (doping 
TABLE I. Standard parameters of the different $\mathrm{SiN}_{\mathrm{x}}: \mathrm{H}$ deposition techniques used.

\begin{tabular}{|c|c|c|c|}
\hline & Centrotherm A & Centrotherm B & $\begin{array}{c}\text { Roth \& } \\
\text { Rau SiNA }\end{array}$ \\
\hline Plasma & direct & direct & remote \\
\hline Frequency & $40 \mathrm{kHz}$ & $40 \mathrm{kHz}$ & $2.45 \mathrm{GHz}$ \\
\hline Temperature & $450^{\circ} \mathrm{C}$ & $450^{\circ} \mathrm{C}$ & $400^{\circ} \mathrm{C}$ \\
\hline Duration & $\sim 45 \mathrm{~min}$ & $\sim 45 \mathrm{~min}$ & $<10 \min$ \\
\hline Gas flow ratio $\mathrm{SiH}_{4}: \mathrm{NH}_{3}$ & $1: 5.5$ & $1: 11$ & $1: 3.8$ \\
\hline Refractive index $x_{(633 \mathrm{~nm})}$ & 2.15 & 2.05 & 2.05 \\
\hline Layer thickness & $85 \pm 3 \mathrm{~nm}$ & $73 \pm 3 \mathrm{~nm}$ & $78 \pm 5 \mathrm{~nm}$ \\
\hline
\end{tabular}

concentration $\mathrm{N}_{\mathrm{A}}$ ) every few minutes using a Sinton Instruments WCT 120 lifetime tester. ${ }^{13}$ Lifetime values were converted into normalized defect concentrations $N^{*}(t)$ affected by degradation and regeneration according to

$$
\mathrm{N}^{*}(\mathrm{t})=1 / \tau(\mathrm{t})-1 / \tau_{0}
$$

with $\tau(\mathrm{t})$ being the minority carrier lifetime at time $\mathrm{t}$ and $\tau_{0}$ being the lifetime in the annealed state. The stability of the lifetime after the regeneration procedure has been checked after further illumination at $40^{\circ} \mathrm{C}$ for $24 \mathrm{~h}$. The annealed state was measured (annealing at $200^{\circ} \mathrm{C}$ in the dark for $10 \mathrm{~min}$ ) after the completion of the regeneration cycle in order to avoid any effects that might originate from possible degradation of surface passivation during the degradationregeneration cycle.

\section{EXPERIMENTAL DETAILS AND RESULTS}

\section{A. Variation of gas composition during $\mathrm{SiN}_{\mathrm{x}}: \mathrm{H}$ deposition}

\section{Experimental details}

In the first experiment, silicon wafers (prepared as described in Sec. II) were coated on both sides by $\mathrm{SiN}_{\mathrm{x}}$ :H passivation layers deposited using the direct PECVD technique in a Centrotherm system. We used $\mathrm{SiH}_{4}$ and $\mathrm{NH}_{3}$ as process gases with two different gas flow ratios of 1:5.5 (samples A) and 1:11 (samples B) yielding $\mathrm{SiN}_{\mathrm{x}}: \mathrm{H}$ passivation layers with different densities. ${ }^{14}$ After deposition, some of the samples were treated at $850^{\circ} \mathrm{C}$ (sample peak temperature for $<10 \mathrm{~s}$ ) in an industrial-type fast firing belt furnace from Centrotherm (firing step). Finally, the regeneration procedure was applied as described in Sec. II. The composition of the $\mathrm{SiN}_{\mathrm{x}}: \mathrm{H}$ layers was determined by FTIR spectroscopy and is partly shown in Fig. 1. The higher integrated absorbance of the Si-N peak in the infrared spectrum corresponds to a higher mass density of the layer. ${ }^{15}$ Therefore, Fig. 1 reveals that the $\mathrm{SiN}_{\mathrm{x}}: \mathrm{H}$ layers of samples B are denser than the layers of samples A.

\section{Results}

The evolution of the normalized defect concentration during regeneration is shown in Fig. 2.

As can be seen in Fig. 2, the fired samples show different regeneration time constants of $7.5 \pm 0.5 \mathrm{~min}$ for

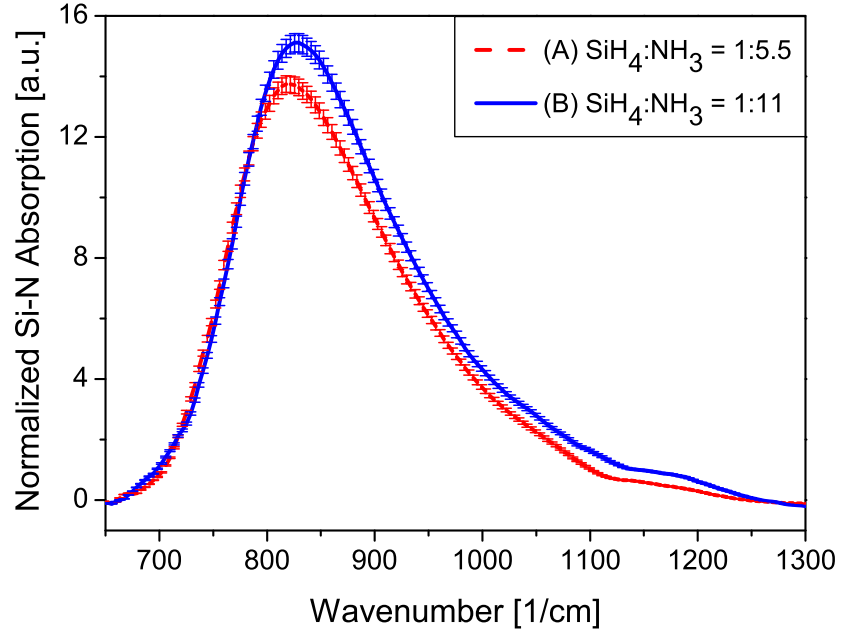

FIG. 1. Absorbance (weighted with layer thickness) of $\mathrm{Si}-\mathrm{N}$ bonds in the $\mathrm{SiN}_{\mathrm{x}}: \mathrm{H}$ layer measured before the short high temperature step. The higher the absorbance of the Si-N peak, the higher is the mass density of the $\mathrm{SiN}_{\mathrm{x}}: \mathrm{H}$ layer.

samples $\mathrm{B}$, and $23 \pm 2 \mathrm{~min}$ for samples $\mathrm{A}$. In either cases, no regeneration effect can be observed for samples without a high temperature firing step after $\mathrm{SiN}_{\mathrm{x}}: \mathrm{H}$ deposition (for the specific $\mathrm{SiN}_{\mathrm{x}}: \mathrm{H}$ used).

\section{Discussion}

As published by Dekkers et al., ${ }^{16}$ a $\mathrm{SiN}_{\mathrm{x}}: \mathrm{H}$ deposition with reduced $\mathrm{NH}_{3}$ flow yields a less dense $\mathrm{SiN}_{\mathrm{x}}: \mathrm{H}$ layer releasing less atomic hydrogen into the silicon bulk during a high temperature firing step. ${ }^{17} \mathrm{Fig} .2$ shows that exactly samples A with lower $\mathrm{Si}-\mathrm{N}$ bond density (gas flow ratio $\mathrm{SiH}_{4}: \mathrm{NH}_{3}=1: 5.5$ ) and therefore a presumably lower concentration of atomic hydrogen in the bulk after the firing step regenerate more slowly than the samples B with a higher Si$\mathrm{N}$ bond concentration $\left(\mathrm{SiH}_{4}: \mathrm{NH}_{3}=1: 11\right)$ and, therefore, higher hydrogen concentration in the bulk.

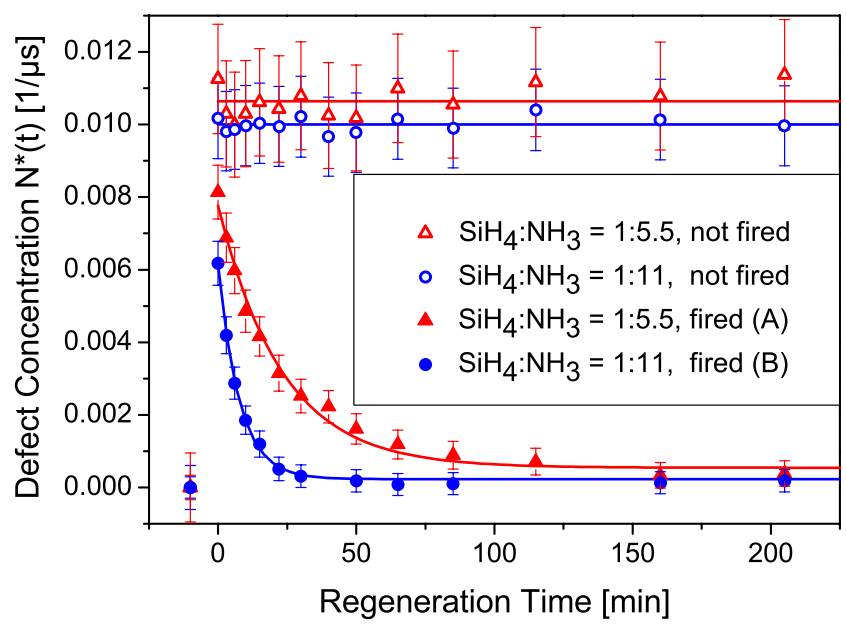

FIG. 2. Comparison of the evolution of the normalized defect concentration $\mathrm{N}^{*}(\mathrm{t})$ during regeneration of samples coated with $\mathrm{SiN}_{\mathrm{x}}: \mathrm{H}$ with two different $\mathrm{SiH}_{4}: \mathrm{NH}_{3}$ ratios during deposition. Only the samples marked by full symbols received a short high temperature firing step after silicon nitride deposition. The first data point represents the annealed state. The lines are exponential fits to the data used for the extraction of characteristic time constants. 
Based on the results of experiment A, we suppose that first, a hydrogen source, namely a hydrogen-rich passivation layer, and second, a temperature step that is able to make hydrogen diffuse from the layer into the silicon bulk distributing it homogeneously with depth, is necessary to make the regeneration process possible in a silicon wafer that had degraded due to the formation of recombination active boron-oxygen related defects.

\section{B. Variation of hydrogen diffusion barrier thickness underneath a $\mathrm{SiN}_{\mathrm{x}}: \mathrm{H}$ layer}

\section{Experimental details}

Further lifetime samples were produced as described in Sec. II, and the described regeneration procedure was applied again. The surface passivation this time was realized by stacks composed of $\mathrm{Al}_{2} \mathrm{O}_{3}$ produced via remote plasma atomic layer deposition (ALD) in a FlexAL reactor from Oxford Instruments and a $\mathrm{SiN}_{\mathrm{x}}: \mathrm{H}$ capping layer produced in a remote plasma SiNA system from Roth \& Rau. The stacks consisted of 8 and $16 \mathrm{~nm} \mathrm{Al}_{2} \mathrm{O}_{3}$, respectively, coated by $60 \mathrm{~nm} \mathrm{SiN}: \mathrm{H}$ and received a high temperature firing step at $820^{\circ} \mathrm{C}$ peak sample temperature. Samples passivated only with $\mathrm{SiN}_{\mathrm{x}}: \mathrm{H}$ or only with $\mathrm{Al}_{2} \mathrm{O}_{3}$ are produced and regenerated the like.

\section{Results}

Results of the regeneration measurements are shown in Fig. 3 and the data from the comparison samples in Fig. 4.

The exponential fits to the data shown in Fig. 4 yield regeneration time constants of $455 \pm 56 \mathrm{~min}$ for the solely $\mathrm{Al}_{2} \mathrm{O}_{3}$ coated sample and $44 \pm 3 \mathrm{~min}$ for both the solely $\mathrm{SiN}_{\mathrm{x}}: \mathrm{H}$-coated sample as well as for the sample coated with a stack using $8 \mathrm{~nm}$ thin $\mathrm{Al}_{2} \mathrm{O}_{3}$. Obviously, the regeneration behavior of the stack with $8 \mathrm{~nm} \mathrm{Al}_{2} \mathrm{O}_{3}$ is dominated by the influence of the $\mathrm{SiN}_{\mathrm{x}}: \mathrm{H}$ capping layer and not affected by the thin $\mathrm{Al}_{2} \mathrm{O}_{3}$ layer underneath it (that only permits a very slow regeneration when used without any capping layer, see Fig. 4). This is in stark contrast to the sample coated with the stack consisting of thicker $\mathrm{Al}_{2} \mathrm{O}_{3}$ that regenerates with a time

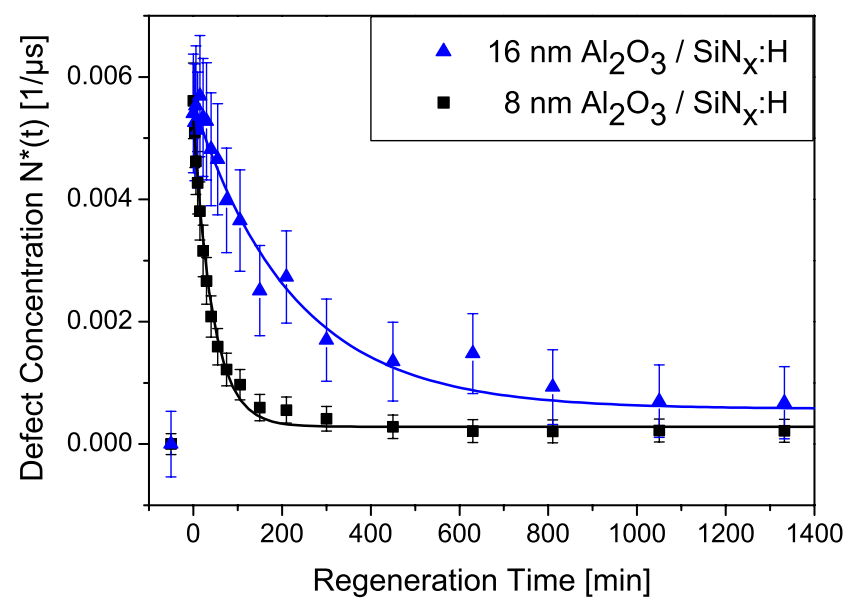

FIG. 3. Regeneration behavior of lifetime samples coated with stacks of $8 \mathrm{~nm}$ and $16 \mathrm{~nm} \mathrm{Al} \mathrm{O}_{3} / \mathrm{SiN}_{\mathrm{x}}: \mathrm{H}$, respectively. The first data points represent the annealed state. The lines are exponential fits to the data.

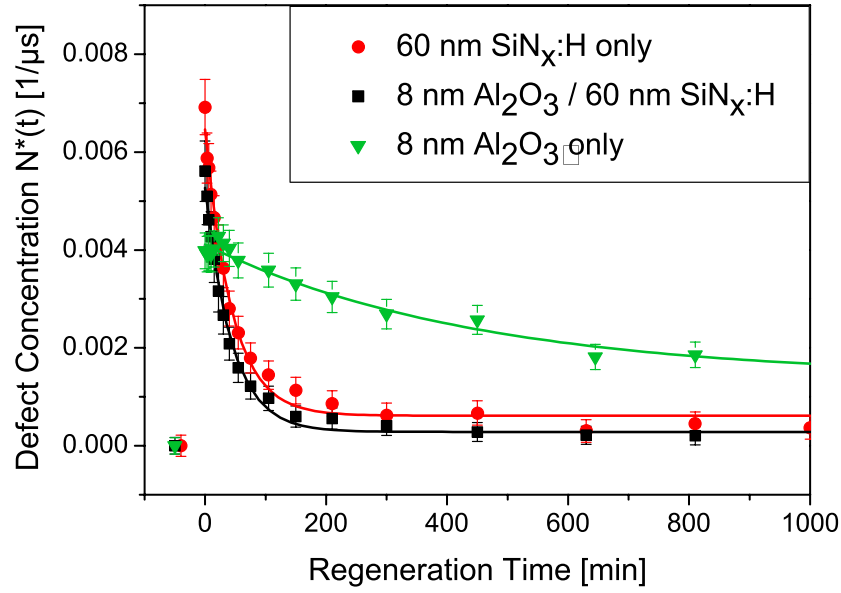

FIG. 4. Regeneration behavior of lifetime samples coated with $\mathrm{SiN}_{\mathrm{x}}: \mathrm{H}$ or with $\mathrm{Al}_{2} \mathrm{O}_{3}$ or with a stack of both. The first data points represent the annealed state. The lines are exponential fits to the data.

constant of $225 \pm 28 \mathrm{~min}$ (Fig. 3). This shows that the presence of a thick enough $\mathrm{Al}_{2} \mathrm{O}_{3}$ layer underneath the capping layer slows down the regeneration process.

\section{Discussion}

As shown by Dameron et al., ${ }^{18}$ transmissibility of ALD$\mathrm{Al}_{2} \mathrm{O}_{3}$ films for atomic hydrogen (determined using tritium atoms) decreases by more than one order of magnitude between 5 and $10 \mathrm{~nm}$ layer thickness. So we expect the thicker stack with $16 \mathrm{~nm} \mathrm{Al}_{2} \mathrm{O}_{3}$ to allow less atomic hydrogen to diffuse from the $\mathrm{SiN}_{\mathrm{x}}$ :H capping layer into the silicon bulk during the short high temperature firing step. Therefore, a different regeneration behavior should be observed for the two stacks if atomic hydrogen is necessary for the regeneration process to occur. The results presented in Fig. 3 support this argumentation: Being a diffusion barrier for atomic hydrogen, a thicker $\mathrm{Al}_{2} \mathrm{O}_{3}$ layer significantly slows down the regeneration process.

\section{Hydrogenation in a Microwave Induced Remote Hydrogen Plasma (MIRHP)}

\section{Experimental details}

Looking at the results presented above, the question arises whether a hydrogenated surface passivation layer treated with a high temperature firing step is the only way to trigger the regeneration effect. We examine this by preparing samples without a possibly hydrogen releasing passivation layer that undergo a cyclic hydrogenation procedure as proposed by Stutzmann et al. ${ }^{19}$

Every cycle consisted of two steps (see Fig. 5): First, the $\mathrm{Cz}$ silicon wafers were tempered for $20 \mathrm{~h}$ at $170^{\circ} \mathrm{C}$ in a remote hydrogen plasma using a MIRHP reactor. ${ }^{20}$ This step aims at passivating the boron atoms with hydrogen in the first few microns of the sample. Second, the samples were tempered in nitrogen atmosphere for $1 \mathrm{~h}$ at $250^{\circ} \mathrm{C}$ in order to make the boron atoms release the hydrogen that got bound to them during the first step and to make the hydrogen diffuse further into the sample. The boron atoms are then mostly unpassivated again. Stutzmann et al. showed that this 
method can be applied in a cyclic way (we applied it up to five times) with the number of hydrogen atoms in the sample being augmented with every cycle. ${ }^{19}$ Thus, a set of samples with different hydrogen contents, depending on the number of cycles they had seen, can be produced. The amount of hydrogen atoms that are able to enter the bulk per cycle depends directly on the number of boron atoms that could be passivated in the first few microns during the $170^{\circ} \mathrm{C}$ MIRHP step. For highly doped samples (around $1 \times 10^{19} \mathrm{~cm}^{-3}$ ), Stutzmann et al. found a linear dependence between the number of hydrogenation cycles and the hydrogen concentration in the silicon bulk. ${ }^{19}$ We assume that comparable processes take place in the $2 \Omega \mathrm{cm}\left(\sim 7 \cdot 10^{15} \mathrm{~cm}^{-3}\right)$ material we used.

Finally, all samples were tempered at $200^{\circ} \mathrm{C}$ for $5 \mathrm{~h}$ in the dark in order to make the hydrogen atoms distribute more homogeneously in the whole sample and to make sure that all boron-oxygen related defects are in the annealed state. ${ }^{21}$ Then, all samples were degraded completely and subsequently regenerated for 8 and $20 \mathrm{~min}$ at $130^{\circ} \mathrm{C}, 0.6$ suns. According to experience (e.g., Fig. 2), this leads to a regeneration of $90 \%$ of the recombination active defects in well hydrogenated $\mathrm{POCl}_{3}$ gettered samples.

Each regeneration step was followed by brief chemical polishing of the surfaces (in order to get a completely new wafer surface) and Piranha-cleaning (mixture of $\mathrm{H}_{2} \mathrm{SO}_{4}$ and $\mathrm{H}_{2} \mathrm{O}_{2}$ ); thereafter surfaces were wet chemically passivated by a quinhydrone-methanol solution. ${ }^{22}$ Minority carrier lifetime was measured and homogeneity of the surface passivation was monitored by photoluminescence imaging (used to calculate the error bars given in Fig. 6). Finally, half the samples were annealed and the others were destabilized and then completely degraded again. The whole wet chemical passivation procedure was reapplied in order to measure minority carrier lifetime in the annealed and the degraded state, respectively. Some wafers broke and could, therefore, not be

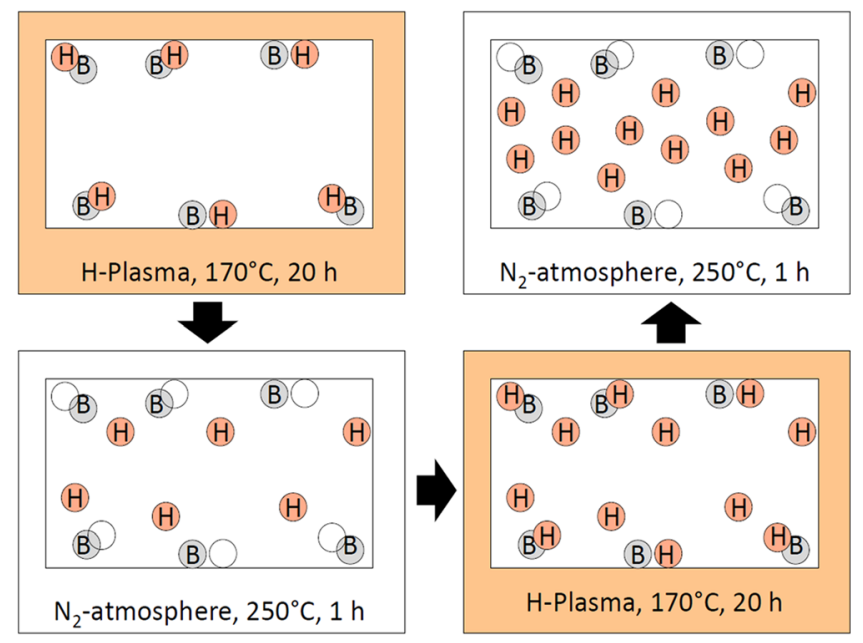

FIG. 5. Illustration of the first two hydrogenation cycles. Top left: Hydrogen passivation of boron atoms in the first few microns $\left(170^{\circ} \mathrm{C}\right)$. Bottom left: Indiffusion of hydrogen into the sample bulk $\left(250^{\circ} \mathrm{C}\right)$. The boron atoms in the first few microns can trap hydrogen again. Bottom right: Re-passivation of boron atoms in the first few microns $\left(170^{\circ} \mathrm{C}\right)$. Top right: Further indiffusion of hydrogen into the bulk. Cyclic application of those steps yields an augmented hydrogen concentration in the bulk.

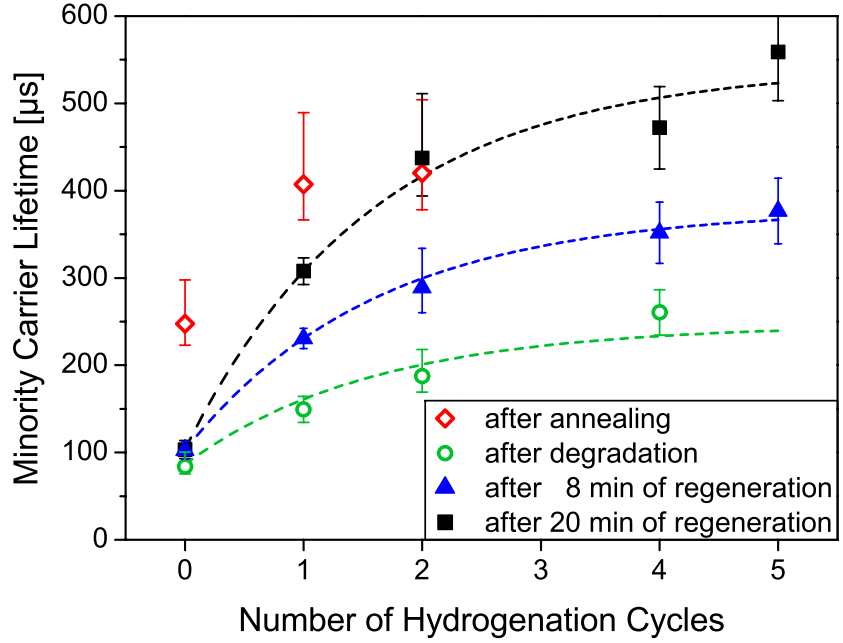

FIG. 6. Minority carrier lifetime values measured after annealing, degradation, 8 and $20 \mathrm{~min}$ of regeneration for samples that had seen different numbers of hydrogenation cycles. The samples were wet chemically surface passivated. The large error bars are mainly due to a lack of homogeneity of the chemical surface passivation. The lines are guides to the eye.

measured in these states. An overview of all measured lifetime values is presented in Fig. 6 .

\section{Results}

Our measurement data (see Fig. 6) show that the minority carrier lifetime measured after 8 and $20 \mathrm{~min}$ increases with increasing number of hydrogenation cycles that the respective samples had seen prior to the regeneration procedure. The samples that had not seen any hydrogenation did not show any improvement in carrier lifetime after the regeneration durations applied here and thus stayed in the degraded state. The samples that had undergone one hydrogenation cycle reached a lifetime value between the degraded and the annealed state, the samples having seen two hydrogenation cycles actually reached the lifetime value of the annealed state (within the measurement uncertainty) after $20 \mathrm{~min}$ of regeneration. We ascribe the measured changes in minority carrier lifetime to the regeneration effect, and based on the findings of Stutzmann et al., ${ }^{19}$ we believe that the number of cycles correlates with the hydrogen content of the silicon bulk. Unfortunately, the sparse resolution of only two regeneration data points at 8 and $20 \mathrm{~min}$ leaves open, whether the effect is due to a change in regeneration rate or alternatively a change in saturation value. Nevertheless, the influence of the presented hydrogenation method is clear.

\section{Discussion}

In experiment $\mathrm{C}$, a hydrogenation method that is not based on a hydrogenated passivation layer is applied. The only thing the two methods have in common is the presence of a plasma containing hydrogen. Whereas in experiment A, we investigated how changes in the deposition conditions of $\mathrm{SiN}_{\mathrm{x}}: \mathrm{H}$ layers are influencing the ability of the respective samples to regenerate; in experiment $\mathrm{C}$, we create a set of samples with different hydrogen contents in the silicon bulk. 
So the similarity of the results coming from the different experiments despite the very different sample preparation backs up the hypothesis that the presence of hydrogen in the silicon bulk is a necessary condition for the regeneration effect to occur. In addition to that, experiment $\mathrm{C}$ reveals that a higher hydrogen concentration facilitates the regeneration process-at least up to a certain concentration that is yet to determine.

\section{THE NEW FINDINGS IN THE CONTEXT OF OTHER PUBLISHED RESULTS}

Finally, results published by Lim et al. ${ }^{8}$ should be taken into account. Lim et al. have shown that a phosphorus gettering step speeds up the regeneration effect (we can confirm this by data not presented here). This step is performed in order to reduce the concentration of (metallic) impurities in a silicon wafer. On the other hand, those impurities are known to be traps for atomic hydrogen: ${ }^{23}$ Depending on the conditions, they are able to slow down hydrogen diffusion (by temporarily trapping hydrogen atoms) or to bind hydrogen atoms to them permanently. If we suppose-based on the results presented here-that more mobile atomic hydrogen in the silicon bulk allows a faster regeneration, it seems logical that the more hydrogen trapping impurities are present in the material, the more the regeneration process is hindered due to competing trapping reactions. Further research is needed to investigate if the observed effect of a phosphorus diffusion is really due to impurity gettering or if it can also be induced by using a comparable temperature step in a phosphorus-free atmosphere.

In summary, we conclude: A high enough concentration of mobile atomic hydrogen in a silicon wafer is necessary to make any boron-oxygen related regeneration effect possible, with a higher hydrogen concentration allowing a faster regeneration. Impurities might cause competing reactions and thus slow down the regeneration process.

\section{TOWARDS A NEW REGENERATION MODEL}

The regeneration effect can only take place under carrier injection at slightly elevated temperatures exeeding $60{ }^{\circ} \mathrm{C} .{ }^{4}$ Considering the data published earlier by Münzer ${ }^{9}$ and the new data presented in this work, it seems reasonable to add a third constraint: the presence of (a sufficient amount of) hydrogen in the silicon bulk. So the question arises how the recombination active boron-oxygen complex gets inactive under the influence of temperature, carrier injection, and hydrogen.

\section{A. Hydrogen}

It is still unclear how the crucial interaction between the boron-oxygen defect and hydrogen takes place. Mainly two possibilities are to be considered: Either hydrogen is directly involved, as we propose, or it is a catalyst for at least one of the physical processes occurring during regeneration. In the first case, this step might be a classical hydrogen passivation, meaning hydrogen capture by the $\mathrm{BO}$ complex. In the latter case, hydrogen might somehow promote or make possible the dissolution of the $\mathrm{BO}$ complex as proposed by Voronkov et al. ${ }^{24}$

\section{B. Temperature}

The need for elevated temperatures implies that higher energies are needed for any of the components to overcome an energy barrier. Hydrogen is a good candidate that may be able to diffuse sufficient distances in silicon at temperatures as low as $60^{\circ} \mathrm{C}$. The fact that regeneration follows an Arrhenius correlation for temperatures between 60 and $200{ }^{\circ} \mathrm{C}$ (Ref. 4) makes the participation of a diffusion mechanism probable. Nevertheless, one might rather talk about a two-step process here instead of a normal diffusion-limited process. This assumption is supported by the fact that the attempt frequency that Herguth et al. ${ }^{21}$ obtained from temperature dependent regeneration measurements is in the order of $10^{7} \mathrm{~s}^{-1}$ and thus much lower than one would expect in the case of a simple diffusion mechanism induced by lattice vibrations $\left(\sim 10^{14} \mathrm{~s}^{-1}\right)$. So we propose that regeneration is triggered by the diffusion of atomic hydrogen that is enhanced by slightly elevated temperatures.

\section{Carrier injection}

At the temperatures needed for regeneration to occur, most hydrogen atoms in the silicon bulk are present as molecules or bound to impurities like boron, oxygen, or carbon. ${ }^{23}$ But hydrogen can only be mobile enough at such low temperatures in its atomic form. So if regeneration relies on the presence of mobile atomic hydrogen, those hydrogen molecules have to be split or hydrogen atoms have to be released from impurities. Since for most impurities as well as for hydrogen molecules, the binding energies exceed $1.1 \mathrm{eV},{ }^{23}$ the thermal energy at $60^{\circ} \mathrm{C}$ is statistically not high enough to realize that without further assistance. Hence, the carrier injection necessary for the regeneration process may indicate a carrier-enhanced detachment of hydrogen atoms from each other or from impurities, maybe due to a change of the charge state of hydrogen atoms. In addition to that, a carrier enhanced diffusion mechanism depending on the hydrogen charge state is thinkable.

Therefore, these three conditions interact and are all necessary (and as far as we know sufficient) for the regeneration process to occur in silicon wafers that had degraded due to the formation of boron-oxygen related recombination active defects.

\section{THE DESTABILIZATION PROCESS IN THIS MODEL}

It has been reported that the regenerated state can be completely destabilized by tempering the sample for more than $4 \mathrm{~h}$ at $200{ }^{\circ} \mathrm{C}$ in dark. ${ }^{21}$ Thereafter, the sample is in the instable annealed state again. The characteristic frequency calculated by Herguth et al. ${ }^{21}$ from temperature dependent destabilization measurements has been determined to be in the range of $10^{7} \mathrm{~s}^{-1}$, which makes a two-step process thinkable for the destabilization. In the H-passivation model, this would correspond to a combination of hydrogen leaving the BO complex and the complex itself changing its 
configuration (as proposed by Vorkonkov et al. for the annealing step). ${ }^{24}$ This means that the activation energy of the destabilization, which has been determined to be $\mathrm{E}_{\mathrm{a}}=1.00 \pm 0.03 \mathrm{eV},{ }^{21}$ would correspond to the binding energy of $\mathrm{H}$ to the $\mathrm{BO}$ complex. For comparison, the binding energy of hydrogen to boron in crystalline silicon is reported to be about $1.1 \mathrm{eV}^{23}$

\section{CONCLUSION}

We have shown results from regeneration measurements using boron doped $\mathrm{Cz}$ silicon wafers into which hydrogen was inserted under substantially different conditions. All shown results can be explained by the insertion of hydrogen into the bulk during high temperature steps. ${ }^{15,16,18,19}$ Against this background, our results lead to the finding that no or at least only an extremely slow regeneration is possible, unless there is a considerable amount of mobile atomic hydrogen available in the silicon bulk during the regeneration procedure. In addition to that, the characteristic time constant of the regeneration process seems to depend on the amount of mobile atomic hydrogen present in the silicon bulk with more hydrogen allowing a faster regeneration. Finally, we presented a model about how the factors hydrogen, temperature, and carrier injection might interact during the regeneration of boron-oxygen related defect centers. This leads to a better understanding of the regeneration process and the conditions under which this effect occurs. Furthermore, it is now possible to control the regeneration kinetics by purposefully varying hydrogen content, temperature, and carrier injection. A direct consequence is that knowledge about how different process steps influence the hydrogen content of a silicon wafer can be used in order to predict the possibility to regenerate a specific sample.

\section{ACKNOWLEDGMENTS}

The authors would like to thank S. Joos, A. Hammud, L. Mahlstaedt, J. Ranzmeyer, and A. Frey for technical support during sample preparation and characterization. Part of this work was supported by the German Federal Ministry for the Environment, Nature Conservation and Nuclear Safety.

${ }^{1} \mathrm{H}$. Fischer and W. Pschunder, in Proceedings of the 10th IEEE PVSC, Palo Alto, CA (1973), p. 404.

${ }^{2}$ S. W. Glunz, S. Rein, W. Warta, J. Knobloch, and W. Wettling, Sol. Energy Mater. Sol. Cells 65, 219 (2001).

${ }^{3}$ K. Bothe and J. Schmidt, J. Appl. Phys. 99, 013701 (2006).

${ }^{4}$ A. Herguth, G. Schubert, M. Kaes, and G. Hahn, in Proceedings of the 32nd IEEE PVSC (4th WCPEC), Waikoloa, USA (2006), p. 940.

${ }^{5}$ A. Herguth, G. Schubert, M. Kaes, and G. Hahn, Prog. Photovoltaics 16, 135 (2007).

${ }^{6}$ B. Lim, A. Liu, D. Macdonald, K. Bothe, and J. Schmidt, Appl. Phys. Lett. 95, 232109 (2009).

${ }^{7}$ B. Lim, K. Bothe, and J. Schmidt, J. Appl. Phys. 107, 123707 (2010).

${ }^{8}$ B. Lim, K. Bothe, and J. Schmidt, Phys. Status Solidi (RRL) 2(3), 93 (2008).

${ }^{9} \mathrm{~K}$. A. Münzer, in Proceedings of the 24th EU-PVSEC, Hamburg, Germany (2009), p. 1558.

${ }^{10}$ B. Lim, K. Bothe, and J. Schmidt, Semicond. Sci. Technol. 26, 095009 (2011).

${ }^{11} \mathrm{~J}$. Schmidt, K. Bothe, and R. Hezel, in Proceedings of the 3rd WCPEC, Osaka, Japan (2003), p. 919.

${ }^{12}$ A. Herguth and G. Hahn, J. Appl. Phys. 108, 114509 (2010).

${ }^{13}$ R. A. Sinton and A. Cuevas, Appl. Phys. Lett. 69(17), 2510 (1996).

${ }^{14}$ J.-F. Lelièvre, E. Fourmond, A. Kaminski, O. Palais, D. Ballutaud, and M. Lemiti, Sol. Energy Mater. Sol. Cells 93, 1281 (2009).

${ }^{15}$ A. J. M. van Erven, Master Thesis, Eindhoven University of Technology, 2004.

${ }^{16}$ H. F. Dekkers, G. Beaucarne, M. Hiller, H. Charifi, and A. Slaoui, Appl. Phys. Lett. 89, 211914 (2006).

${ }^{17}$ H. F. W. Dekkers, L. Carnel, and G. Beaucarne, Appl. Phys. Lett. 89, 013508 (2006).

${ }^{18}$ A. A. Dameron, S. D. Davidson, B. B. Burton, P. F. Carcia, R. S. McLean, and S. M. George, J. Phys. Chem. C 112, 4573 (2008).

${ }^{19}$ M. Stutzmann, W. Beyer, L. Tapfer, and C. P. Herrero, Physica B 170, 240 (1991).

${ }^{20}$ M. Spiegel, P. Fath, K. Peter, B. Buck, G. Willeke, and E. Bucher, in 13th EU-PVSEC, Nice, France (1995), p. 421.

${ }^{21}$ A. Herguth, G. Schubert, M. Kaes, and G. Hahn, in Proceedings of the 21st EU-PVSEC, Dresden, Germany (2006), p. 530.

${ }^{22}$ M. Solcansky, M. Machacek, J. Bousek, and A. Poruba, in Proceedings of the 24th EU-PVSEC, Hamburg, Germany (2009), p. 1669.

${ }^{23}$ S. J. Pearton, J. W. Corbett, and T. S. Shi, Appl. Phys. A 43, 153 (1987).

${ }^{24}$ V. V. Voronkov and R. Falster, J. Appl. Phys. 107, 053509 (2010). 